\title{
PROPOSTA DE ZONEAMENTO GEOAMBIENTAL PARA O MUNICÍPIO DE CARAGUATATUBA - SP
}

\author{
Cibele Oliveira Lima ${ }^{1}$ \\ Regina Célia de Oliveira²
}

\begin{abstract}
Resumo: O município de Caraguatatuba sempre apresentou diversidade de uso e ocupação da terra, que ao longo dos anos resultou em diversos níveis de impactos modificando a dinâmica natural. Esse artigo propõe a implementação de um padrão espacial que leve em consideração uma estrutura especial de ordenamento territorial, e seja coerente com as potencialidades e limitações locais. Considerando a necessidade de uso dos recursos e serviços, desde que ocorram sempre de forma racional, buscou-se a estabilidade da dinâmica dos sistemas, através da limitação da ação dos processos ambientais degradantes. A partir da metodologia de Geoecologia da Paisagem proposta por Rodriguez et. al. (2007) e dos princípios da legislação aplicada no município é apresentada uma proposta de Geoambiental em escala 1:50.000.
\end{abstract}

Palavras-chave: Zoneamento Geoambiental; Geoecologia da Paisagem; Zona Costeira;

Caraguatatuba

\section{PROPOSAL OF ENVIRONMENTAL ZONING FOR THE MUNICIPAL DISTRICT OF CARAGUATATUBA-SP}

\begin{abstract}
The municipal district of Caraguatatuba always presented a diversity of land use and occupation, which resulted in several levels of impacts modifying the natural dynamics along the years. This paper proposes the implementation of a space pattern that takes into account a special structure of land management that is coherent with the local potentialities and limitations. Considering the need of using the resources and services, once they happen in a rational way, the goal is to find the dynamics stability of the systems, through the limitation of degradading environmental processes. Using the methodology of Landscape Geoecology proposed by Rodriguez et. al. (2004) and considering the applied legislation, it is presented a proposal of an Environmental Zoning in scale 1:50.000.
\end{abstract}

Keywords: Environmental Zoning; Landscape Geoecology; Coastal Zone; Caraguatatuba

\footnotetext{
${ }^{1}$ Doutoranda em Geografia. Universidade Federal de Santa Catarina. Email: cibele.col@gmail.com ${ }^{2}$ Professora Doutora do Departamento de Geografia da Universidade Estadual de Campinas. Email: reginacoliveira@ige.unicamp.br
} 


\section{PROPUESTA DE ORDENAMIENTO AMBIENTAL PARA LA CIUDAD DE CARAGUATATUBA - SP}

Resumen: El distrito municipal de Caraguatatuba presenta diversidad de uso y ocupación de la tierra, que a lo largo de los años resultaron en muchos niveles de impacto modificadores de la dinámica natural. Ese artículo propone la puesta en práctica de un patrón espacial que tenga en cuenta una estructura especial de ordenamiento territorial, que sea coherente con las potencialidades y las limitaciones locales. Considerando la necesidad de uso de los recursos y los servicios, desde que ocurran en una manera sensata, la estabilidad de la dinámica de los sistemas fue buscada, a través de la limitación de la acción de los procesos ambientales degradantes. Utilizando la metodología de Geoecologia del Paisaje propuesta por Rodriguez et. al. (2007) y los principios de la legislación de la ciudad, se presenta una propuesta de ordenamiento ambiental en escala 1:50.000.

Palabras clave: Ordenamiento Geoambiental; Geoecología del Paisaje; Zona Costera;

Caraguatatuba

\section{Introdução}

Atualmente a preocupação em aliar o potencial natural e econômico-social com a fragilidade ambiental vêm recebendo cada vez mais atenção por parte do planejamento ambiental, que realiza a tentativa de encontrar o equilíbrio por meio de seus instrumentos de aplicabilidade, como o zoneamento ambiental.

O zoneamento se constitui como um método integrador de informações ambientais e se caracteriza como a "identificação e delimitação de unidades ambientais em um determinado espaço físico, segundo suas vocações e fragilidades, acertos e conflitos, determinadas a partir dos elementos que compõem o meio planejado" (SILVA e SANTOS, 2004, p.227).

Nesse sentido o objetivo principal do zoneamento é delimitar unidades com diferentes normas específicas para a implementação de diversos tipos de atividades e conservação do meio em que se encontram. No entanto, deve ser mais do que apenas identificar, classificar e delimitar atributos em um território; deve ser também a integração do resultado de análises dinâmicas e de regionalizações desse território (CAVIDAD GARCIA, 1991).

Dessa forma o zoneamento possui caráter interdisciplinar integrando um enfoque mais analítico, referente a definição da regionalização e a produção de inventários e diagnósticos temáticos dos principais atributos, com um enfoque sistêmico mais atrelado à forma e estrutura dessa integração nos produtos finais. Ross (1994) aponta a importância da integração das disciplinas técnico-científicas na elaboração de ordenamentos territoriais que 
possam adequar os programas de desenvolvimento e os meios institucionais a uma relação harmônica entre sociedade e natureza.

Esse artigo tomou como principal ponto de partida o Zoneamento Ambiental, elencado como um dos instrumentos da Política Nacional do Meio Ambiente e apontado na Lei Federal $\mathrm{n}^{\circ} 6.938$ de 31 de agosto de 1981, que levava em consideração inicialmente apenas o aspecto preservacionista. No entanto, quando da edição do decreto federal $n^{\circ} 4.297 / 2002$, evoluiu para Zoneamento Ecológico Econômico (ZEE), na tentativa de englobar as questões sociais e econômicas.

Silva e Santos (2004) ressaltam ainda que o Zoneamento Ambiental deve assegurar, mesmo que a longo prazo, a igualdade de acesso aos recursos naturais, econômicos e socioculturais sem, no entanto, expor o meio ambiente ao esgotamento. E mais do que isso, para que ele possa servir para a gestão do território, deve prever a preservação, recuperação e melhoria da qualidade ambiental como base do desenvolvimento socioeconômico e da proteção da dignidade humana.

Uma de suas vertentes, o Zoneamento Geoambiental, objetivo desse trabalho, possui nomenclatura diferenciada para ressaltar a importância de se considerar os elementos e aspectos naturais do meio físico e biótico como base para um planejamento de ordem ambiental. Para tal, deve-se definir as zonas ou unidades ambientais através do estudo e análise de um conjunto amplo de critérios, de forma a encontrar a integração dos elementos do meio dando significado as zonas.

Para Naveh e Lieberman (1994) a delimitação das zonas ambientais ocorre através de uma organização hierárquica da natureza e da inter-relação entre os fatores ambientais (geologia, solo, uso da terra, vegetação, etc.), sendo que a interação entre os fatores ambientais deve ser entendida a partir da análise dos fluxos de energia e matéria entre os componentes da natureza e da sociedade.

Levando em consideração esse contexto de zoneamento ambiental, foi escolhido o município de Caraguatatuba como área de estudo para a elaboração de uma proposta de zoneamento. Localizado no litoral norte do Estado de São Paulo, faz divisa com os municípios de São Sebastião, Ubatuba, Natividade da Serra, Paraibuna e Salesópolis, com acesso pela Rodovia Tamoios (SP-099) e pela Rodovia Osvaldo Cruz (SP-125) (Figura 1). 


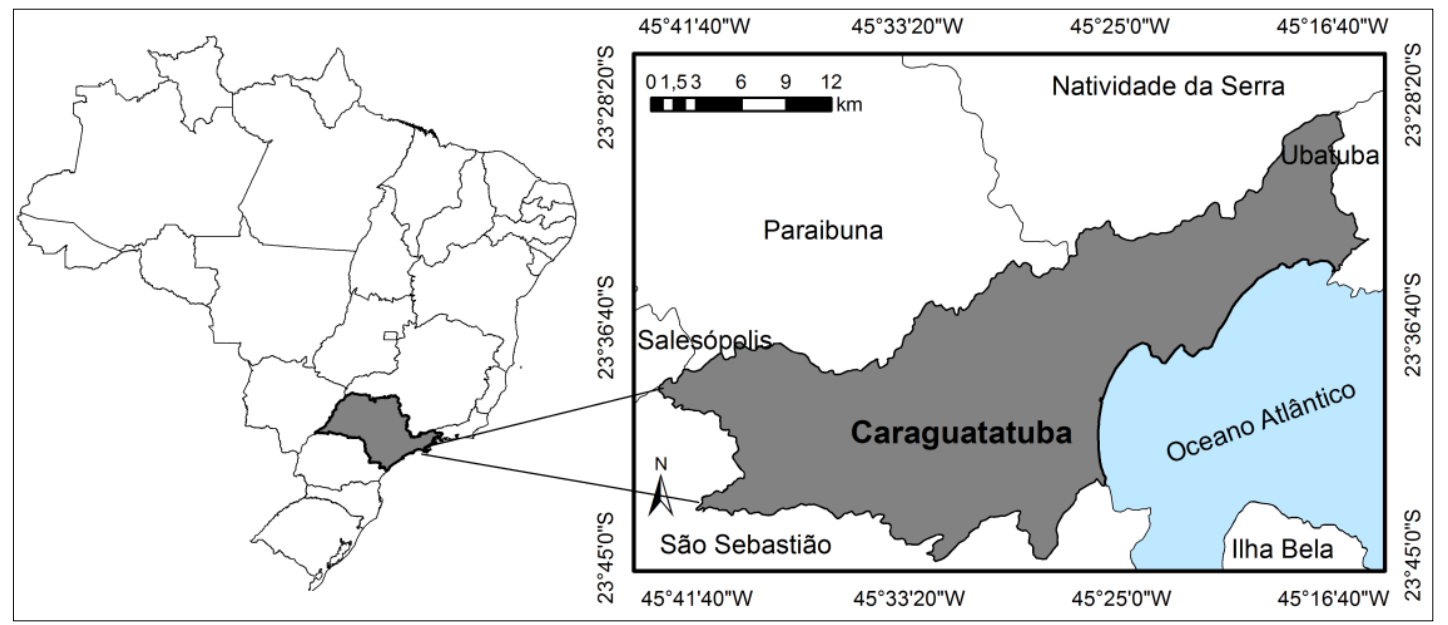

Figura 1: Localização do município de Caraguatatuba. Fonte: Elaborada pelos autores, 2017.

O município está localizado na Região Administrativa de São José dos Campos e na Região de Governo de Caraguatatuba a cerca de $180 \mathrm{~km}$ da capital paulista. Além disso, Caraguatatuba faz parte da Região Metropolitana do Vale do Paraíba e Litoral Norte, recentemente instituída por meio da Lei Estadual Complementar n ${ }^{\circ} 1166$ de 9/01/2012.

A estância balneária do município de Caraguatatuba possui cerca de 100.000 habitantes distribuídos em uma área de $484 \mathrm{~km}^{2}$, representando o maior e mais importante polo comercial do litoral Norte, além de constituir polo turístico reconhecido pela beleza das praias e por fazer parte do Parque Estadual da Serra do Mar, constituindo ainda reserva ecológica de espécies da Mata Atlântica (PMC, 2017).

No que diz respeito a legislação, o município de Caraguatatuba está inserido no Gerenciamento Costeiro, cujo processo de institucionalização ocorreu com a Lei Federal $n^{\circ}$ 7.661 de 16 de maio de 1988 que estabeleceu o Plano Nacional de Gerenciamento CosteiroPNGC como parte integrante da Política Nacional do Meio Ambiente-PNMA e da Política Nacional de Recursos do Mar-PNRM. O objetivo primordial é orientar a utilização racional dos recursos da zona costeira de forma a contribuir para elevar a qualidade de vida de sua população e a proteção do seu patrimônio natural, histórico, étnico e cultural. Atualmente, como parte dessa política de planejamento, o município responde ao disposto no Zoneamento Ecológico Econômico do Litoral Norte Paulista, que apresenta pontos de interesse significativo para esse trabalho (SMA, 2005). 
Um desses pontos é o fato de que conforme o Zoneamento Ecológico Econômico, fazse necessário garantir a manutenção da diversidade biológica e do patrimônio histórico, paisagístico, cultural e arqueológico; promover programas de controle da poluição das nascentes e vegetação ciliar para garantir quantidade e qualidade das águas; promover a regularização fundiária; fomentar o manejo autossustentável dos recursos ambientais nas áreas de vegetação em estágio avançado de regeneração e fauna associada, que possuam alteração de cerca de $10 \%$ da cobertura vegetal, e restrições do Dec. Fed. 750/93, declividade média acima de 47\%, com restrições da Lei Fed. 4.771/65 e Res. Conama 303/02; e nos casos de existência de comunidades tradicionais; Unidade de Proteção Integral e manguezais, com restrições da Lei Fed. 4.771/65 e Res. Conama 303/02 (SMA, 2005).

Ainda de acordo com SMA (2005), nas áreas de proteção ambiental do Parque Estadual da Serra do Mar somente são permitidos os usos definidos na legislação que regula as categorias das Unidades de Conservação, no diploma legal que as criou e nos respectivos Planos de Manejo, quando aplicáveis, ou seja, ações que garantam a manutenção das características próprias do ambiente e as interações entre os seus componentes.

Outro ponto importante a se considerar é que segundo o ZEE torna-se necessário manter a funcionalidade dos ecossistemas garantindo a conservação dos recursos genéticos e promovendo programas de manutenção, controle da poluição e proteção das nascentes e da vegetação ciliar para garantir quantidade e qualidade das águas nas áreas com elevada recorrência de áreas de preservação permanente, com restrições da Lei 4.771/65, e de riscos geotécnicos; vegetação em estágio avançado de regeneração e fauna associada, ocorrência de supressão ou de alteração de até $30 \%$ de cobertura vegetal, com restrições do Dec. Fed. 750/93; declividade média entre 30\% e 47\% e sujeitas à inundação (SÃO PAULO, 1996).

O contexto apresentado do município de Caraguatatuba serviu de apoio para a proposta de zoneamento geoambiental apresentada nesse artigo, de forma a lhe conceder um caráter de ferramenta de planejamento integrado, que possa representar uma contribuição para o ordenamento do uso racional dos recursos, garantindo a manutenção da biodiversidade, dos processos naturais e de serviços ambientais ecossistêmicos.

Portanto, esse artigo justifica-se pela sua contribuição aos estudos de natureza geoambiental, com o intuito de apontar áreas de fragilidade ambiental frente a necessidade social, contribuindo para planos de disciplinamento de uso que além de intervir com menor 
risco possível na sociedade possam promover também a manutenção da qualidade dos sistemas naturais costeiros.

\section{Desenvolvimento}

\section{Metodologia e Procedimentos operacionais}

A concepção dos Geossistemas amplamente utilizada nesse artigo surge com a aplicação da Teoria Geral dos Sistemas na Geografia Física, sendo que Christofoletti (1979) entende que eles representam a organização espacial resultante da interação entre os elementos físicos e biológicos da natureza.

Já Sotchava (1977) entende o geossistema como um tipo de método analítico de estudo das formas naturais (físicas, ambientais e bióticas) em que a ação antrópica representa parte integrante e significativa de análise, sendo então necessário o estudo dos fatores naturais a luz dos fatores econômicos e sociais que influenciam os mesmos. Rodrigues (2001) complementa afirmando que as influências antropogenéticas representam o estado de mudança do geossistema em relação ao seu estado original.

Tendo a abordagem sistêmica como base metodológica, a elaboração do zoneamento ambiental foi realizada a partir da delimitação e caracterização das unidades da paisagem com sistemas semelhantes de funcionamento.

Esse artigo focou na metodologia de delimitação das unidades de paisagem proposta por Rodriguez et. al. (2004), fundamentada nas argumentações de Sotchava (1977 e 1978), que afirma que a análise da paisagem deve ser realizada a partir do estudo dos geossistemas, cuja natureza passa a ser compreendida pelas conexões entre eles priorizando além da morfologia da paisagem e suas subdivisões, a análise de sua dinâmica, estrutura funcional e conexões.

A unidade de paisagem representa então uma porção ou subdivisão do geossistema, composta por um conjunto de subsistemas com grau elevado de similaridade das características físicas e bióticas, bem como de sua dinâmica de funcionamento. A delimitação das unidades de paisagem é de suma importância pois é a base para realizar o zoneamento ambiental, uma vez que será a partir delas e para cada uma delas que serão identificados os problemas ambientais para posteriormente propor normas individuais e específicas para o desenvolvimento de atividades e conservação do meio em cada uma delas. 
A proposta de zoneamento ambiental realizada por Rodriguez et. al. (2004) considera cinco enfoques principais na análise da paisagem: o Estrutural, o Evolutivo Dinâmico, o Antrópico, o Integrativo da Estabilidade e Sustentabilidade e o enfoque Funcional da Paisagem. Esse artigo adotou o enfoque Funcional da Análise da Paisagem, que tem como finalidade esclarecer como a paisagem é estruturada, indicando as relações funcionais dos seus elementos e o motivo de estarem estruturados de tal forma.

Neste enfoque todos os elementos possuem funções determinadas no processo de gênese da paisagem e de formação do geocomplexo. A interação desses elementos e processos no tempo é um fator significativo na formação e funcionamento da paisagem e é representada através de um processo de trocas de energia e substância, consideradas como funções geoecológicas dos geossistemas.

Os procedimentos operacionais foram realizados de acordo com as seguintes fases da metodologia de Geoecologia da Paisagem (Figura 2) organizada por Rodriguez et. al. (2004).

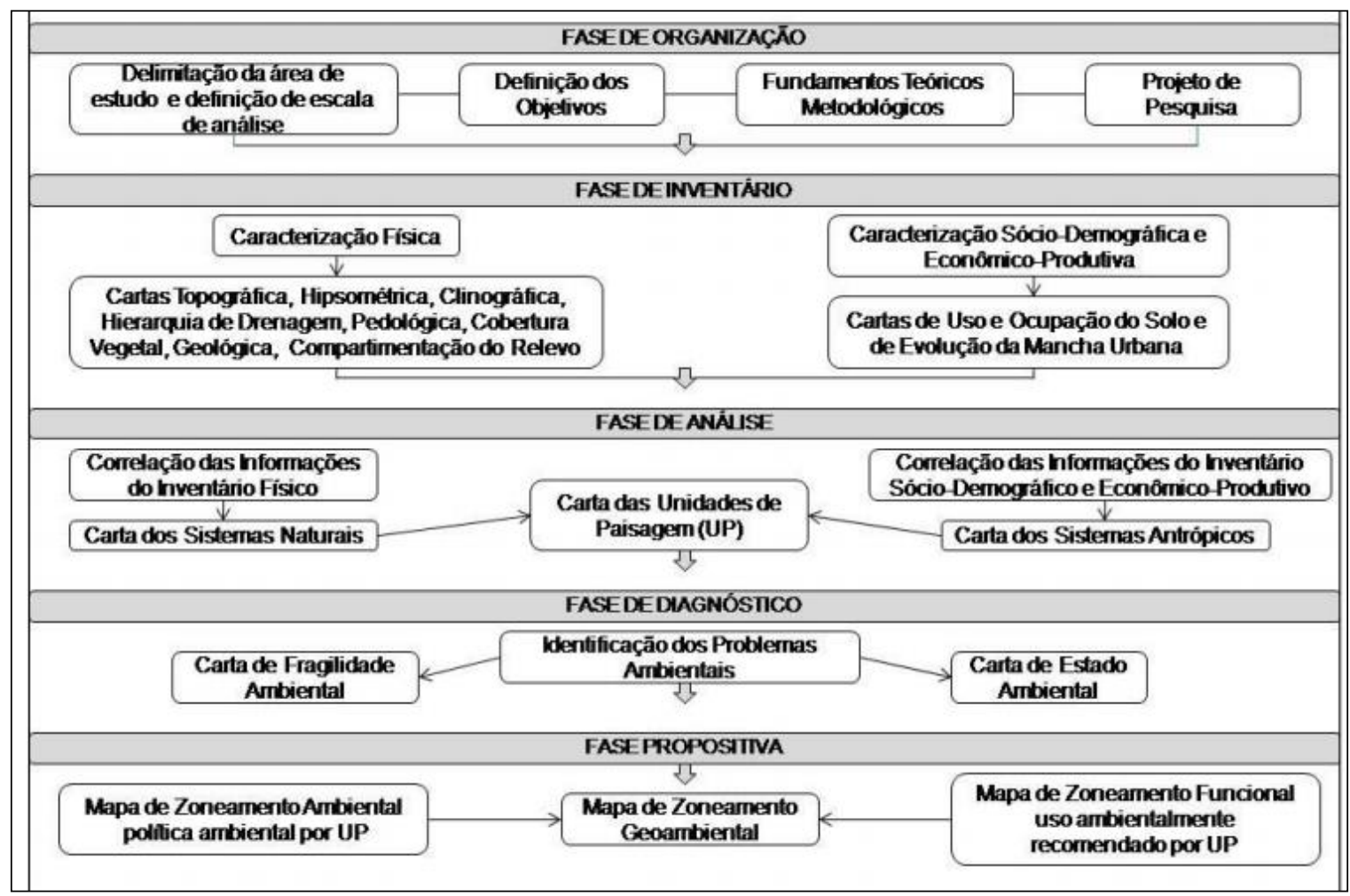


Figura 2: Diagrama Metodológico. Fonte: Adaptada pelos autores de Rodriguez et. al. (2004).

$\mathrm{Na}$ fase de organização, foi delimitado o objeto, a área e a escala que foi trabalhada, no caso um Zoneamento Geoambiental do município de Caraguatatuba em escala 1:50.000.

$\mathrm{Na}$ fase de inventário, foi feito o levantamento dos dados naturais e socioeconômicos visando o entendimento da organização espacial e funcional dos sistemas, para elaboração da cartografia básica, de fundamental importância para a definição, classificação e cartografia das unidades de paisagem. Foram elaboradas e organizadas as cartas de topografia, hierarquia de drenagem, hipsometria, declividade, unidades geológicas, cobertura vegetal natural, pedologia, geomorfologia, uso e ocupação da terra e evolução da mancha urbana.

$\mathrm{Na}$ fase de análise foi realizado o tratamento dos dados obtidos na fase anterior através da integração dos componentes naturais e socioeconômicos, permitindo a confecção da carta síntese de Sistemas Naturais e de Sistemas Antrópicos, com as informações referentes a cada sistema sobrepostas. Essas cartas serviram de base referencial para a identificação dos setores de riscos e dos principais conflitos e impactos ambientais.

Finalizada a produção cartográfica e estudo das informações levantadas nas fases de inventário e análise, foi possível dar prosseguimento a seguinte etapa denominada diagnóstico, na qual foi identificada a problemática ambiental e a qualidade da paisagem, fornecendo um diagnóstico integrado.

Foi produzida então a Carta de Unidades de Paisagem do município de Caraguatatuba, a fim de identificar e diferenciar áreas homogêneas em relação a processos naturais e 
antrópicos, sintetizando os resultados obtidos na fase de análise, possibilitando a integração dos aspectos naturais e antrópicos.

As unidades de paisagem foram delimitadas com base na dinâmica de fluxo de matéria e energia dos sistemas naturais, considerando as unidades de relevo, associadas a dinâmica de ocupação dos sistemas antrópicos, por meio da classificação da função da ocupação em categorias. Assim foi realizada uma junção das unidades de Topos, Escarpas, Morros Isolados e Planície Costeira com as diferentes categorias de uso antrópico: mata atlântica, mangue, restinga, praia, pasto, mineração e área urbana consolidada e inconsolidada. Foram definidas 13 unidades de paisagem para o município, com características semelhantes entre si, como pode ser observado na Figura 3 abaixo.

\begin{tabular}{|c|c|c|c|c|c|c|c|c|}
\hline \multirow{2}{*}{$\begin{array}{l}\text { Uso da } \\
\text { Unidades } \\
\text { Naturais }\end{array}$} & \multirow{2}{*}{$\begin{array}{c}\text { Mata } \\
\text { Atlântica }\end{array}$} & \multirow{2}{*}{ Mangue } & \multirow{2}{*}{ Restinga } & \multirow{2}{*}{ Praia } & \multirow{2}{*}{$\begin{array}{c}\text { Agro- } \\
\text { pecuaria }\end{array}$} & \multirow{2}{*}{ Mineração } & \multicolumn{2}{|c|}{ Área Urbana } \\
\hline & & & & & & & \begin{tabular}{|c|} 
Consolidada \\
\end{tabular} & Inconsolida \\
\hline Topos & 1 & & & & & & & \\
\hline Morros Residuais & 2 & & & & & & 3 & \\
\hline Escarpas & 4 & & & & & 5 & & 6 \\
\hline Planície Costeira & & 7 & 8 & 9 & 10 & 13 & 11 & 12 \\
\hline
\end{tabular}

Figura 3: Unidades de Paisagem do município de Caraguatatuba-SP. Fonte: Elaborada pelos autores, 2017.

Para tornar o diagnóstico mais detalhado e realizar uma síntese das fragilidades naturais da área de estudo, priorizando as informações mais atuais e de escala mais compatível com a usada na pesquisa, foi produzida a Carta de Fragilidade Ambiental. Definiu-se que os critérios que condicionantes da fragilidade ambiental de cada unidade de paisagem no município de Caraguatatuba são litologia, declividade e do uso da terra, quantificados e analisados em igual peso, através do uso de uma matriz com a combinação e classificação desses critérios para cada unidade, possibilitando a classificação em graus de fragilidade ambiental segundo a proposta de Rodriguez et. al. (2004).

Posteriormente, ainda dentro do diagnóstico integrado, foi analisado o impacto dos diferentes usos da terra nos sistemas naturais com o intuito de produzir a Carta de Estado Ambiental do município de Caraguatatuba, que representa os níveis de estabilidade dos sistemas naturais em função da ação antrópica de acordo com os supracitados.

Para a confecção dessa carta foi primeiramente elaborada uma tabela com os problemas ambientais para cada unidade de paisagem da área de estudo, a partir da qual foi avaliada a 
ocorrência e intensidade dos problemas ambientais de acordo com a gravidade de sua manifestação e o caráter de sua distribuição espacial. A análise quantitativa dos problemas ambientais possibilitou a atribuição de valores de estado ambiental para cada unidade de paisagem, classificando-as de acordo com metodologia dos autores citados acima.

Finalmente, na fase de proposição, foi elaborada a carta de zoneamento geoambiental, a partir da delimitação de polígonos com unidades de paisagem com fragilidade e estado ambiental semelhante. Tem a função de uma carta síntese produzida a partir da correlação do grau de estabilidade das unidades de paisagem com a dinâmica de funcionamento do sistema ambiental.

O Zoneamento Ambiental, que se caracteriza como um instrumento de gestão, foi dividido em cinco zonas: Unidades de Proteção Ambiental, Conservação Ambiental, Melhoramento Ambiental, Conservação e estímulo ao desenvolvimento local e Reabilitação Ambiental. Com o auxílio da legislação, foi estabelecida a funcionalidade de cada zona junto com uma proposta de uso denominada de Zoneamento Funcional, com as seguintes categorias: Vegetação Original, Ecoturismo, Urbano, Mineração, Agropecuário e Reflorestamento.

\section{Resultados}

O zoneamento geoambiental (Figura 4), proposto nesse trabalho, buscou definir zonas para possíveis usos de acordo com as características das unidades de paisagem, a fragilidade e o estado ambiental, além da legislação vigente.

O Município de Caraguatatuba está inserido em uma região de domínio da Floresta Ombrófila Densa com $74,98 \%$ de seu território coberto por vegetação natural. Parte desta biodiversidade está situada na planície costeira de $32 \mathrm{~km}$, a maior do litoral norte, com fragmentos de ecossistemas associados de restinga e manguezais. Essas características, juntamente da existência de uma riquíssima biota marinha, justificam a criação de diversas unidades de conservação no Município de Caraguatatuba (SMA, 2005).

O PESM (Parque Estadual da Serra do Mar) foi criado pelo Decreto n ${ }^{\circ} 10.251$ de 31 de agosto de 1977 e é administrado pela Fundação para a Conservação e a Produção Florestal do Estado de São Paulo (Fundação Florestal). É o maior parque do Estado de São Paulo, e 
também, a maior unidade de conservação de proteção integral de toda a Mata Atlântica, sendo responsável pela proteção de grande parte da área de estudo.

No zoneamento aqui proposto, todas as unidades de paisagem com Mata Atlântica, seja nos topos, escarpas ou nos morros residuais foram definidas como unidades de proteção ambiental, nas quais os principais usos propostos são a manutenção da vegetação original e a melhoria na infraestrutura para o ecoturismo. Cabe salientar que o ecoturismo deve ser realizado de forma controlada, planejada e monitorada por agentes especializados garantindo a preservação do meio ambiente e a segurança dos turistas, o que aponta a necessidade de capacitação de pessoal relacionado a fiscalização e vigilância. 

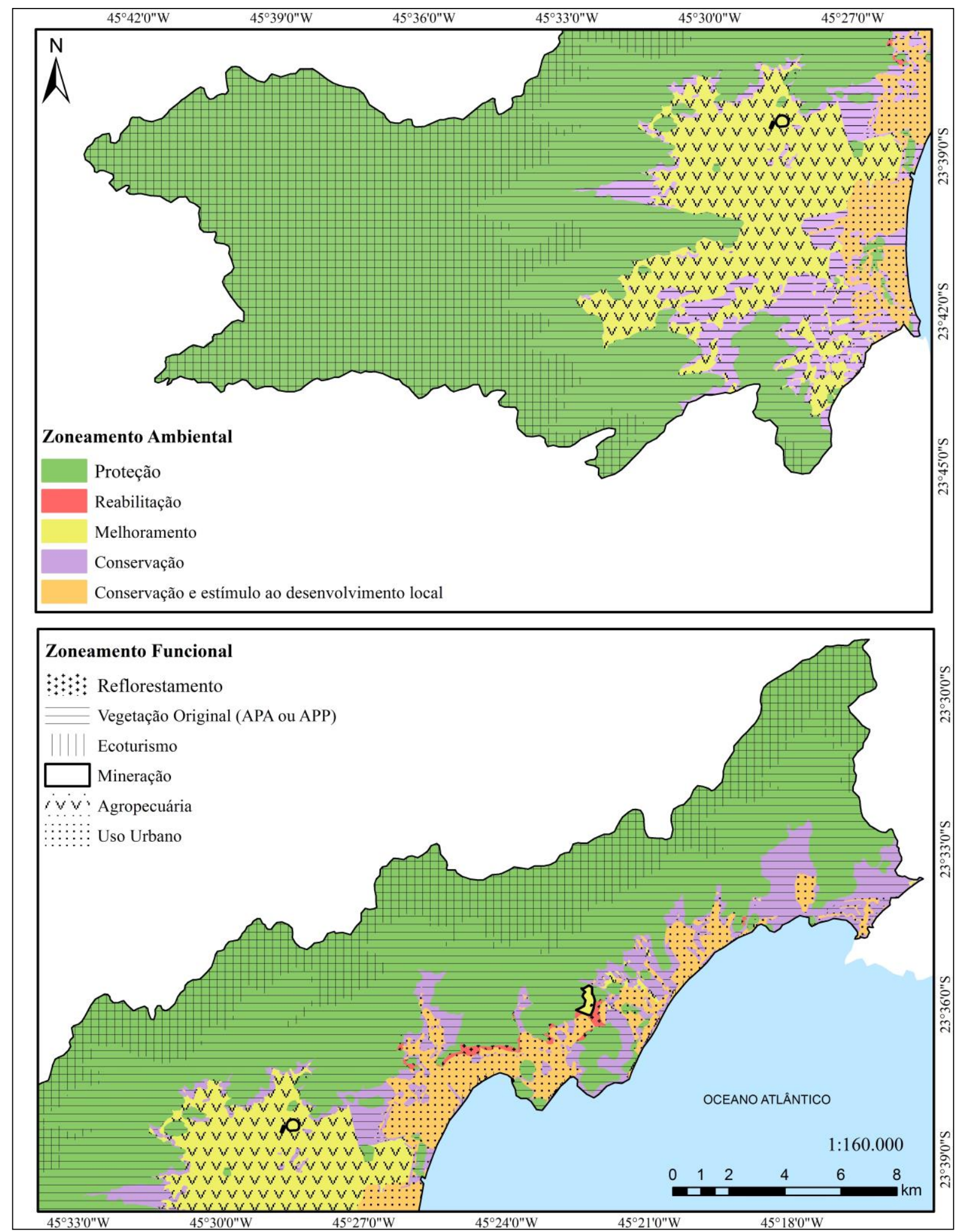

Figura 4: Zoneamento Geoambiental do município de Caraguatatuba-SP. Fonte: elaborada pelos autores, 2017. 
Cabe salientar que já existe uma Zona de Amortecimento (ZA) do PESM, que foi delimitada a partir de $10 \mathrm{~km}$ contados do limite da Unidade de Conservação e inclui grande parte da área urbanizável do município de Caraguatatuba. Foram excluídas da ZA a área urbana consolidada e a área de expansão urbana prevista no antigo Plano Diretor do Município (SMA, 2005). Isso causa problemas com relação a algumas instalações que estão dentro do limite da área de proteção como a Pedreira Massaguaçu e a Unidade de Tratamento de Gás da Petrobras.

Ainda no âmbito das Áreas de Proteção Permanente do município, além daquelas com declividade superior a $45^{\circ}$ que fazem parte do Parque Estadual da Serra do Mar, há as APP de margem de rio que representam domínio de um dos ecossistemas mais frágeis e raros do planeta: o manguezal. O maior problema relacionado à ocupação desse tipo de APP são os aterros para ocupação urbana, que foram responsáveis pela supressão de $95 \%$ das áreas de manguezais do município (CARAGUATATUBA, 2012).

Pela urgência em manter o ecossistema do mangue na região, que apesar de estar protegido por lei no âmbito das Áreas de Preservação Permanente, apresenta apenas alguns remanescentes no município, essa proposta de zoneamento definiu sua unidade de paisagem como unidade de proteção ambiental. Os manguezais encontram-se na planície costeira e por serem áreas na interface entre o continente e o oceano, são consideradas ao mesmo tempo transmissoras e receptoras de matéria e energia e possuem frágil dinâmica e instabilidade natural. Por isso faz-se necessário manter o uso de sua vegetação original e monitorar sua preservação, já que tem enorme importância na manutenção da biodiversidade e se encontra em áreas cada vez mais pressionadas pelo aumento da urbanização.

Continuando no âmbito dos remanescentes de vegetações originais do município de Caraguatatuba propõe-se a criação de uma unidade de conservação ambiental capaz de proteger ao menos parte das áreas de restinga, uma vez que é a unidade de paisagem mais suscetível a ação antrópica e que se encontra fora das legislações de proteção ambiental do Parque Estadual da Serra do Mar e das Áreas de Preservação Permanente dos Manguezais.

O trecho a seguir justifica a criação de áreas de conservação para a restinga no município uma vez que representa alguns fragmentos de resoluções do CONAMA (004/1993 e 417/2009) a respeito da importância delas, que já são consideradas como área de preservação na legislação federal. 
Art. 1o Passam a ser de caráter emergencial, para fins de zoneamento e proteção, todas as áreas de formações nativas de restinga, [...] considerando a importância biológica, incluindo endemismos, espécies raras e ameaçadas de extinção existentes; a singularidade da fisionomia e das belezas cênicas; a distribuição geográfica restrita; e o elevado grau de ameaça a que está submetida a vegetação de Restinga em função das ações antrópicas (CONAMA, 2009).

Caraguatatuba apresenta a maior planície costeira do litoral norte de São Paulo, englobando fragmentos de ecossistemas associados de restinga e manguezal e é considerada a área mais propícia à expansão urbana de todo o litoral norte, com a presença de áreas de centros urbanos, praias e zonas agropastoris. Tal situação configura uma disputa pela apropriação do espaço que tem por um lado a imperativa obrigatoriedade de se preservar o ambiente natural para as presentes e futuras gerações e por outro a necessidade de se garantir estoques de terra para a crescente expansão urbana do município.

Quanto às áreas de ocupação urbana da planície costeira é possível afirmar que a regulação do ordenamento territorial é determinada por diversas leis municipais, especialmente pela Lei Orgânica (1990) e pelo Plano Diretor do Município, instituído na Lei complementar municipal $n^{\circ} 42$ de 24 de novembro de 2011, constituindo-se, de fato, como o principal instrumento da política urbana municipal. Ambos estabelecem regras e princípios para o ordenamento territorial, e definem macrozonas com zoneamentos específicos, que norteiam as políticas de proteção ambiental e ocupação urbana.

De acordo com o Plano Diretor (2011), o território do Município está dividido em dois (art.102): Macrozona de Proteção Ambiental constituída pelo Parque Estadual da Serra do Mar e Macrozona de Desenvolvimento Urbano destinada ao desenvolvimento da ocupação urbana. Seus parâmetros de uso e ocupação da terra são regulados de forma extensa pelo próprio Plano Diretor, especialmente pelo Título VI (arts.119 e seguintes).

$\mathrm{Na}$ macrozona de desenvolvimento urbano percebe-se o estabelecimento de dois tipos de padrões principais no que diz respeito a configuração espacial: áreas consolidadas e inconsolidadas. 
As áreas urbanas consolidadas são aquelas estabelecidas desde longa data e que apresentam saneamento básico e serviços de coleta de lixo e esgoto, ou seja, possuem infraestrutura de serviços básicos e acesso a transporte e educação, estando ainda inseridas em locais com maior organização espacial. Nessas áreas há além do centro comercial e residências permanentes um número considerável de residências de veraneio.

Já as áreas urbanas com ocupação inconsolidada representam locais com ocupação mais recente em que a infraestrutura urbana ainda não foi estabelecida, havendo falta de serviços adequados e regularizados de abastecimento de água e energia, asfaltamento de vias públicas, além de infraestrutura de transportes e serviços escassa. Nessas áreas predominam moradias de baixo padrão, algumas vezes irregulares. Se encontram nas periferias da cidade, principalmente ao sul e nas proximidades da Serra do Mar.

Segundo São Paulo (2011), existe em Caraguatatuba um grande problema com relação a drenagem urbana em função das ocupações irregulares em áreas inundáveis, onde as residências estão expostas a risco de solapamento de margens de curso d'água ou de escorregamento de encostas como no bairro Jaraguazinho, Ilha do Sol e Rio do Ouro. Há ainda algumas áreas que inundam quando o volume de água é grande na cabeceira e a maré está alta, transbordando o rio em vários pontos, como é caso do Bairro Jardim Santa Rosa, localizado muito próximo ao mar em áreas de baixada de antigo manguezal, que inundam frequentemente, como visto em campo na área.

Portanto, para as áreas urbanas da planície de ocupação consolidada propõe-se a criação de unidades de conservação e estímulo ao desenvolvimento local, uma vez que a população já está ali instalada com dinâmicas já estabelecidas. Nesse caso a conservação diz respeito a manutenção da infraestrutura básica do centro urbano, buscando maior efetividade e diminuindo ou erradicando possibilidade de contaminação de rios e corpos d'água e acúmulo de resíduos sólidos, que trazem prejuízos ao sistema antrópico e à qualidade de vida da população, sem mencionar as alterações que promovem no sistema natural. Como zoneamento funcional propõe-se a revitalização urbana e a conservação do patrimônio histórico.

As áreas urbanas da planície de ocupação inconsolidada também devem ser consideradas como unidades de conservação e estímulo ao desenvolvimento local e necessitam da aplicação de um uso urbano bem estruturado e organizado. Para isso são 
necessárias obras de melhoria da infraestrutura urbana, políticas de situação de risco e de regularização de casas.

Quanto às áreas de ocupação voltada ao turismo, como as praias, propõe-se além da criação de unidades de conservação e estímulo ao desenvolvimento local um incentivo turístico as atividades características de um município litorâneo como o ecoturismo e a preservação do patrimônio histórico e cultural. Para isso torna-se importante um ordenamento em termos de construção e regulamentação no que diz respeito a estabelecimentos relacionados a atividade turística, como pousadas, hotéis, agências de turismo, aluguel de equipamentos, casas de veraneio e etc.

Foi observado que as praias da área de estudo encontram-se em sua maior parte ocupadas e possuem boa infraestrutura de serviços no que diz respeito a organização espacial. O turismo de temporada no município tem importante papel nos investimentos direcionados nessa área. As praias se encontram relativamente limpas e com infraestrutura para turismo com calçadão, áreas de lazer com quadras, pistas de corrida, quiosques para venda de alimentação e banheiros públicos, principalmente nas praias do centro.

Sobre as obras públicas, durante o trabalho de campo foi possível observar uma obra de contenção do avanço do mar na rodovia SP-55 no trecho que liga Caraguatatuba e Ubatuba, mais precisamente na praia de Massaguaçu. Nos meses de inverno a ressaca do mar é responsável pela destruição total da praia, chegando a alagar e a ameaçar a infraestrutura da rodovia. Por esse motivo os taludes estão sendo protegidos com a instalação de molhes de pedra com o objetivo de conter a ação das ondas.

Quanto ao uso agropastoril, a chamada Baixada do Rio Juqueriquerê possui uso do solo predominante de pastagem que engloba uma extensa área pertencente à Fazenda Serra Mar (antiga Fazenda dos Ingleses) com criação de gados bovinos para corte.

Além das áreas de pastagem há também pequenos fragmentos de áreas agrícolas, principalmente na região do bairro Rio Claro e de Massaguaçu e adjacências, onde há, uma produção bastante diversificada de agricultura familiar que inclui berinjela, banana, milho, mandioca, gengibre, pepino, pimentão, pimenta, palmito, cana-de-açúcar, café, jiló, coco, chicória e feijão, todos vendidos ao próprio município (CARAGUATATUBA, 2016).

O Zoneamento Geoambiental proposto para essas áreas é a formação de unidades de melhoramento ambiental com o objetivo de alcançar estabilidade para esse sistema, uma vez 
que o mesmo foi modificado e teve seu equilíbrio alterado. Propõe-se então o estabelecimento de usos agropecuários com o menor dano possível ao sistema natural, utilizando técnicas de manejo verde e alteração não somente nos ciclos de plantio, mas também nas culturas cultivadas, podendo assim oferecer um descanso a terra.

Outro uso que exige bastante da terra na área de estudo é a mineração, executada pela Serveng e pela Pedreira Massaguaçu. Essa última representa a atividade econômica mais contestada pelos ambientalistas, já que a extração mineral é uma atividade contrária aos princípios de uma unidade de conservação de proteção integral como a do Parque Estadual da Serra do Mar. Os impactos ambientais causados por esta atividade vão desde a deterioração da paisagem, o desmatamento e a poluição do ar (emissões de partículas e/ou de gases na atmosfera) até a emissão de ruídos e vibrações decorrentes do funcionamento dos equipamentos e detonações, o que acaba por afastar espécies da fauna silvestre das zonas próximas a pedreira.

Entretanto, a manutenção das operações da Pedreira Massaguaçu, ainda que dentro da área do Parque Estadual, no complexo granítico da Serra do Papagaio, se dá em função de ser a principal fonte de abastecimento de rocha britada para o atendimento da construção civil do litoral norte, região esta que, tem demandado e demandará nos próximos anos, uma quantidade significativa de agregados minerais (areia e rocha britada) para o atendimento da construção civil.

Já as instalações da Serveng Mineração são responsáveis por fornecer materiais usinados de concreto e areia de construção para todo o litoral norte do estado de São Paulo e, por estar localizada na planície em áreas estáveis e fora de unidades de proteção ambiental, representam menor impacto ambiental do que as atividades da Pedreira de Massaguaçu.

Portanto ambas as unidades de paisagem com a presença de mineração também devem constituir unidades de melhoramento ambiental uma vez que apesar dos usos e finalidades serem caracterizados como de utilidade pública conflitam com os objetivos de conservação da área protegida e influenciam diretamente nos processos ecológicos. $\mathrm{O}$ zoneamento funcional para essas áreas é manter o uso da mineração, aprimorando suas técnicas e introduzindo novas tecnologias capazes de racionalizar a exploração dos recursos naturais juntamente da maior proteção ao meio ambiente, buscando assim uma situação de estabilidade ao sistema ambiental local. Propõe-se ainda zonas de amortecimento entre a mineração e as áreas de 
Mata Atlântica do Parque Estadual da Serra do Mar, contribuindo para a preservação da qualidade de vida da fauna silvestre.

Além das áreas de mineração existem algumas outras que merecem atenção especial como as obras de grande importância para o desenvolvimento socioeconômico e urbanístico do município de Caraguatatuba: a duplicação da Rodovia dos Tamoios (SP-099), o Contorno viário Sul (entre São Sebastião e Caraguatatuba) e Norte (entre Caraguatatuba e Ubatuba), e a dutovia. Todos esses empreendimentos implicarão em um grande impacto ao meio ambiente e por isso devem ser realizados de forma racionalizada, levando em consideração as Leis de Proteção ao Meio Ambiente, principalmente no que diz respeito ao Parque Estadual da Serra do Mar, que será a área mais atingida.

Além disso outra área especial é da Unidade de Tratamento de Gás da Petrobras de Caraguatatuba (UTGCA), que apesar de ter suas instalações principais completamente desconectadas da malha urbana existente, se encontra em uma região muito próxima à área de proteção da Serra do Mar, tendo inclusive alguns de seus dutos e pequenas bases passando a menos de $2 \mathrm{~m}$ da área de proteção do manguezal. Há uma crescente preocupação, pois já existem futuros investimentos para a ampliação da Unidade de Tratamento de Gás visando atender as necessidades do pré-sal, o que provavelmente acarretará um impacto maior ainda sobre o território.

Todos esses empreendimentos são necessários ao desenvolvimento local do município, além de serem responsáveis pela retirada de residências em áreas de alto risco de escorregamento e inundação como é o caso do Bairro de Cantagalo e Jardim Santa Rosa, cujas casas já possuem inclusive cadastro no CDHU e seus moradores serão realocados o mais rápido possível para residências seguras.

Portanto, tendo em vista a relevância dessas obras, propõe-se que essas áreas sejam classificadas como unidades de melhoramento ambiental, buscando a implantação desses empreendimentos em conjunto com o cumprimento das leis ambientais, tendo inclusive acompanhamento e fiscalização para as atividades que serão desenvolvidas depois de realizadas as obras, de modo que esteja em conformidade com a manutenção do equilíbrio do sistema ambiental local.

Diferentemente da zona de melhoramento ambiental, que visa uma estabilidade do sistema que ainda não foi fortemente modificado pela ação antrópica, por meio de medidas 
que tornem o uso da terra menos agressivo, na zona de reabilitação ambiental é necessária uma completa alteração no tipo de uso, que deve ser substituído por outro mais apropriado para as áreas em questão, como será observado a seguir

O crescimento da mancha urbana de Caraguatatuba seguiu basicamente dois vetores: um longitudinal ao longo da rodovia SP-55 (Dr. Manoel Hyppólito Rego Jr) paralelamente à orla marítima e outro transversal, da orla marítima em direção à Serra do Mar. A urbanização se deu predominantemente na área de planície entre o mar e a Serra, no entanto ao longo dos anos a pressão urbana foi responsável pelo avanço da área ocupada sobre as encostas mais íngremes das serras, fator preocupante, já que essa ocupação é caracterizada em geral por assentamentos precários, muitos deles, localizados em áreas de risco.

O zoneamento proposto leva em conta a necessidade de excluir ou limitar o uso em algumas áreas, consideradas de risco para a população e ambientalmente frágeis, garantindo segurança aos moradores, durabilidade dos recursos e manutenção dos serviços ambientais locais. Dessa forma, as áreas de escarpas com área urbana inconsolidada necessitam ser removidas e a população direcionada a programas sociais federais como o Minha Casa Minha Vida, o que já vem acontecendo no município com o apoio da prefeitura e defesa civil.

Segundo a Defesa Civil há um total de 19 assentamentos precários no município de Caraguatatuba, localizados nos núcleos Tinga, Jaraguazinho, Rio do Ouro, Benfica, Cantagalo, Casa Branca, Martim de Sá e Olaria, no setor Central do município e Sertão dos Torinhos no setor Sul, todos eles visitados em trabalho de campo.

Essas áreas se constituem como as mais frágeis e críticas ambientalmente, apresentando bairros de ocupação irregular com alto risco, compostos por casas de material misto, alvenaria e madeira, com pouca ou nenhuma organização e estrutura de alicerce fraca. As residências são em sua maioria sobrados improvisados intercalados com casas térreas com padrões irregulares.

Além das áreas em encosta, há também a ocupação do morro residual, que nesse caso se dá por residências consolidadas de médio padrão de urbanização. Apesar das moradias serem bem estruturadas e organizadas e feitas com materiais de qualidade e homogêneos, essas áreas estão localizadas em porções do território com alto risco potencial de escorregamento.

Ambas as áreas, tanto de ocupação inconsolidada nas escarpas como de ocupação consolidada nos morros residuais, devem então ser definidas como áreas de reabilitação 
ambiental. A presença de acentuada declividade, juntamente de sua característica transmissora de matéria e energia, as caracterizam como áreas altamente sujeitas a significativos processos erosivos em terrenos ocupados, o que lhes confere alta instabilidade.

Para a reabilitação ambiental há a necessidade de uma forte alteração no tipo de uso, através de medidas de recuperação do solo ou de reflorestamento, que deve ser feito de forma especial visando a recuperação da vegetação original dessas áreas, introduzindo espécies nativas e contribuindo para sua reinserção nas áreas de proteção ambiental.

\section{Considerações Finais}

Observou-se que a dinâmica de ocupação do município de Caraguatatuba é dada em função do relevo: as planícies costeiras são intensamente ocupadas enquanto a zona de planalto permanece com ocupação incipiente, por se tratar de área de preservação. A zona intermediária das escarpas da Serra do Mar possui extrema fragilidade e vem sofrendo com a intensificação da urbanização pela pressão imobiliária.

Segundo Caraguatatuba (2012) o ritmo de crescimento populacional do município ainda se mantém acelerado com TGCA de 2,49 \% ao ano. Essa tendência leva a um processo de expansão urbana que aumenta as demandas por terras.

A orla do município encontra-se atualmente muito ocupada, de forma descontinua e fragmentada, composta por loteamentos e condomínios de alto padrão que não se conectam e deixam muitas áreas vazias entre os espaços urbanizados. Essas áreas podem servir como reserva de terras já que futuramente sua ocupação pode ser uma alternativa para a expansão da cidade, uma vez que pode integrar os loteamentos usando áreas com vegetação original já modificada, minimizando os impactos.

No entanto, o que pode ser uma solução pode também se caracterizar como a intensificação de um sério problema já existente de moradias irregulares. A especulação imobiliária cada vez maior em um município em que o turismo é o principal motor do desenvolvimento, e no qual, futuros investimentos passam a fazer com que as residências fixas aumentem cada vez mais, tende a fazer com que esses espaços vazios tenham preços cada vez mais altos, principalmente após a instalação de infraestrutura pelo poder público. Essa situação gerará um número maior de excluídos, que ao não terem alternativa, irão se instalar em áreas irregulares, aumentando a pressão sobre as áreas de preservação permanente. 
Além disso, programas de realocação de moradores de áreas de alto risco realizados pela prefeitura do município através da construção de condomínios de CDHU têm apresentado consequências desastrosas tanto para o meio ambiente como para a sociedade. Ao atrair grande contingente de moradores de outros municípios, que se dirigem a Caraguatatuba em busca de melhores condições de habitação, acabam por intensificar o problema de moradia.

Todo esse contexto mostra a necessidade de um rígido controle sobre a ocupação urbana deste município, com o estabelecimento de regras de ordenamento urbano e de construção que garantam uma ocupação adequada às restrições geológicas, ambientais e sociais. Nesse sentido, o zoneamento geoambiental, que surge como uma ferramenta de planejamento integrado, passa a representar uma solução possível para o ordenamento do uso racional dos recursos, garantindo a manutenção da biodiversidade, dos processos naturais e de serviços ambientais ecossistêmicos.

\section{Referências Bibliográficas}

CHRISTOFOLETTI, A. Análise de Sistemas em Geografia. São Paulo, Hucitec: ed. Da Universidade de São Paulo, 1979.

CONSELHO NACIONAL DO MEIO AMBIENTE-CONAMA. Resolução número 417. De 23 de novembro de 2009. D.O.U. 24/11/09.

CARAguAtatuba. Prefeitura Municipal de Caraguatatuba. Relatório de Caracterização das Unidades de Informações Territorializadas - UITs; Sítio acessado em agosto de 2017. Disponível em: http://www.portal.caraguatatuba.sp.gov.br/index.php

CARAGUATATUBA. Prefeitura Municipal de Caraguatatuba. Plano Municipal Plurianual de Desenvolvimento Sustentável Rural e da Pesca. 2016. Disponível em http://www.legislacaocompilada.com.br/caraguatatuba/Arquivo/Documents/legislacao/html/L 23132016.html. Acessado em fevereiro de 2017.

CARAGUATATUBA. Prefeitura Municipal de Caraguatatuba. Resumo Executivo de Caraguatatuba. Litoral Sustentável, Desenvolvimento com Inclusão Social, 2012.

CARAGUATATUBA. Prefeitura Municipal de Caraguatatuba: Plano Diretor, 2011.

CARAGUATATUBA. Prefeitura Municipal de Caraguatatuba. Lei Orgânica do município de Caraguatatuba, 1990.

CADAVID GARCIA, E. A. Zoneamento agroecológico e sócio-econômico da Bacia Hidrográfica Brasileira do rio Paraguai: uma abordagem numérica preliminar (documento para discussão). Corumbá: Embrapa - CPAP, 65 p., 1991.

MORAES, A. C. R. de. Contribuições para a Gestão da Zona Costeira Brasileira. Edusp/Hucitec: São Paulo, 1999. 
MUEHE, G. de C. O Litoral Brasileiro e sua Compartimentação. IN: CUNHA, S. B. e GUERRA, A. Geomorfologia do Brasil, Rio de Janeiro, Bertrand Brasileiro, 1998.

NAVEH, Z.; LIEBERMAN, A. S. Landscape Ecology: theory and application. 2nd ed. New York: Springer-Verlag, 360 p., 1994.

RODRIGUES, C. A teoria geossistêmica e sua contribuição aos estudos geográficos ambientais. Revista do Depto.de Geografia USP. São Paulo, n.14, pp.69-77, 2001.

RODRIGUEZ, J. M. M.; SILVA, E. D.; CAVALCANTI, A. P. B. Geoecologia da paisagem: uma visão geossistêmica da análise ambiental. Fortaleza: EDUFC, 2004.

ROSS, J. .S. Análise Empírica da Fragilidade dos Ambientes Naturais e Antropizados. In: Revista do Depto. de Geografia n ${ }^{\circ}$, FFLCH-USP, São Paulo, 1994.

SÃO PAULO (Estado), Secretaria do Meio Ambiente. Macrozoneamento do Litoral Norte: Plano de Gerenciamento Costeiro, São Paulo, 202 p, Série Documentos, 1996.

SÃO PAULO. Plano Estadual de Habitação de São Paulo, São Paulo, 2011.

SECRETARIA DO MEIO AMBIENTE DE SÃO PAULO. Zoneamento EcológicoEconômico - Litoral Norte. São Paulo: SMA/CPLEA, 2005.

SILVA, J.S.V. \& SANTOS, R.F. Zoneamento para Planejamento Ambiental: Vantagens e restrições de métodos e técnicas. Cadernos de Ciência e Tecnologia, Brasília, v.21, pp.221263, 2004.

SOTCHAVA, V. B. O Estudo de Geossistemas. Métodos em questão. IG-USP. São Paulo, 1977.

SOTCHAVA, V. B. Por uma teoria de classificação de geossistemas de vida terrestre. Biogeografia. IG-USP. São Paulo, 1978.

Recebido em 15 de agosto de 2017.

Aceito em 10 de abril de 2018. 